\title{
Monetary Policy and the Currency Denomination of Debt: A Tale of Two Equilibria
}

\author{
Roberto Chang and Andrés Velasco
}

CID Working Paper No. 106

September 2004

\section{Working Papers Center for International Development at Harvard University}




\title{
Monetary Policy and the Currency Denomination of Debt: A Tale of Two Equilibria*
}

\author{
Roberto Chang ${ }^{\dagger}$ \\ Andrés Velasco $0^{\ddagger}$ \\ Rutgers University \\ KSG, Harvard University
}

This version August 2004

\begin{abstract}
Exchange rate policies depend on portfolio choices, and portfolio choices depend on anticipated exchange rate policies. This opens the door to multiple equilibria in policy regimes. We construct a model in which agents optimally choose to denominate their assets and liabilities either in domestic or in foreign currency. The monetary authority optimally chooses to float or to fix the currency, after portfolios have been chosen. We identify conditions under which both fixing and floating are equilibrium policies: if agents expect fixing and arrange their portfolios accordingly, the monetary authority validates that expectation; the same happens if agents initially expect floating. We also show that a flexible exchange rate Pareto-dominates a fixed one. It follows that social welfare would rise if the monetary authority could precommit to floating.
\end{abstract}

*This paper was prepared for the San Francisco Federal Reserve Bank conference on Emerging Markets, June 2004. We are grateful to Guillermo Calvo, Enrique Mendoza and especially to Maurice Obstfeld, our discussant, for useful comments. We also thank the National Science Foundation for financial support.

$\dagger$ Email: chang@econ.rutgers.edu

‡Email: andres_velasco@harvard.edu 


\section{Introduction}

Emerging market countries have trouble letting their exchange rates float, and many countries that claim to float do not deliver on that promise. That is the conclusion of much recent empirical work, starting with Calvo and Reinhart (2002) and Stein et al. (1999). The reason, these papers argue, ${ }^{1}$ is a lethal mix of dollarization of liabilities and balance sheet effects: if corporate debts are denominated in dollars while firms depend on local currency revenues (or, more precisely, corporate revenues increase with the relative price of goods produced at home), sharp and unexpected changes in relative prices are harmful to financial stability. The policy conclusion is that flexible exchange rates can be destabilizing, and therefore emerging market nations would be well advised to design alternative monetary arrangements, including currency boards and dollarization.

Such a view has become extremely influential, but even its most ardent advocates understand that it is only half the story. The claim is that floating is not feasible given that debts are dollarized. But, presumably, borrowers choose the amounts of debt to issue as peso and dollar-denominated bonds taking into account the risk-return characteristics of these securities. Recognizing that variances and covariances (especially with consumption) should then matter, Ize and Levy-Yeyati (2003), Ize and Parrado (2003), and Morón and Castro (2003) have extended standard portfolio theory to model endogenous dollarization in emerging markets. Their approach, however, takes as given the structure of shocks and, more importantly for our purposes, monetary and exchange rate policies.

So the recent debate has emphasized that exchange rate policies depend on portfolio choices, and also that portfolio choices depend on anticipated exchange rate policies. The next question is inevitable: what are the implications of this interaction once both portfolios and exchange rate policy are endogenous? In particular, what are the resulting policy outcomes? Is there a single outcome, or several ones? These are the issues that this paper focuses on.

We build an extremely simple model of a small open economy in which domestic residents can borrow internationally by issuing bonds denominated in both home and foreign currency. The currency composition of debt plays a nontrivial role because markets are incomplete: bonds are promises to nominal payoffs that can only imperfectly (or not at all) depend on the realization of the state of nature. We also assume sticky wages. Then monetary and exchange rate policy matters through two channels: as in textbook models, in the presence of external shocks, flexible exchange rates stabilize labor supply and output at the expense of making the real exchange rate more volatile; and, as emphasized in the more recent literature, unexpected changes in the real exchange rate may affect wealth and exacerbate the volatility of domestic consumption, if domestic residents are long in one currency and short in the other. As a consequence, the optimal exchange rate policy chosen by a benevolent central bank depends

\footnotetext{
${ }^{1}$ See also Calvo $(1999,2000)$ and Krugman $(1999,2000)$
} 
on the existence and extent of currency mismatches. But the latter are determined, in turn, by the optimizing decisions of domestic borrowers and, hence, by expectations of exchange rate policy.

The equilibrium outcome of this interaction is an exchange rate regime and a market allocation such that the market allocation is a competitive equilibrium given the exchange rate regime, and the central bank cannot increase social welfare by deviating to a different exchange regime. We assume that the central bank chooses the exchange rate regime (whether to fix the nominal exchange rate or to fix the domestic price level and let the exchange rate float) after debts and wage contracts have been written. Then market expectations about exchange rate policy play a crucial role in shaping equilibria.

If bonds are non-contingent promises to either home or foreign currency, we find there is always an equilibrium with floating exchange rates. So, if agents expect the central bank will float, they arrange their wage and debt contracts accordingly; given that, the central bank indeed finds it optimal to float. But in some cases there is also an equilibrium with fixed exchange rates: if agents expect fixed rates, they choose wages and portfolios that make it optimal for the central bank to fix ex post. That is, we can have multiple equilibria in policy regimes.

When there are multiple equilibria, they can be Pareto-ranked. We show that, if utility functions are quadratic or display constant relative risk aversion, the equilibrium involving flexible rates yields higher expected welfare. So if the economy is in a situation in which there are two equilibrium policy regimes, and arbitrary expectations cause the fixed rates equilibrium to materialize, then expected welfare will be inefficiently low. Welfare would increase if the central bank could precommit to float the currency, regardless of the composition of agents' portfolios.

We also study the case in which domestic bonds are indexed to the price of home output. Equilibrium policy regimes turn out to be harder to pin down. Still, under some further assumptions we are able to identify conditions for fixed rates and flexible rates to be equilibrium policy regimes. Again, there is a range of parameters for which both regimes occur in equilibrium. In those cases, a policy of flexible rates again delivers higher expected welfare than do fixed rates.

Our discussion is close in spirit to that in Chamon and Hausmann (2002). In that paper, if domestic firms have large dollar liabilities, unexpected changes in the real exchange rate can drive the firms into costly bankruptcy. The central bank can react to shocks by allowing the interest rate or the exchange rate to move. If domestic firms expect a policy of stable exchange rates they will borrow in dollars, which ex post may cause the monetary authority to validate such expectations for fear of bankrupting the firms. Hence one can have more than one equilibrium policy.

Self-validating policy regimes also appear in Corsetti and Pesenti (2002), but in a very different setting. That paper studies price-setting by firms and the choice of monetary policy by the government. There can be two equilibria. In one, firms preset prices in domestic currency only, and foreign-currency prices are determined by the law of one price. Floating exchange rates are then the 
optimal policy regime. In the second equilibrium firms preset prices in local currency, and a monetary union is the optimal policy choice.

Our policy message here is similar to that in Caballero and Krishnamurty (2004), who analyze a model in which financial market imperfections lead agents to under-provide insurance against liquidity shocks. In that model floating the exchange rate is powerless to ameliorate shocks once the quantity of insurance has been chosen, but can help ex ante to induce agents to take greater precautions against shocks. Hence Caballero and Krishnamurty also argue for precommitting to a float, though for reasons very different from ours.

The next section outlines the basic model, and section 3 presents the basic results. Section 4 extends the analysis to the case in which peso bonds are indexed, while section 5 concludes. Some technical material is delayed to an appendix.

\section{The model}

Consider a single-period, small open economy populated by households and firms. The representative household owns the typical firm and receives its profits.

There are two goods, one produced at home and one produced abroad. The two goods are imperfect substitutes and both tradable. For simplicity, we assume that domestic households consume only the foreign good.

There is a domestic currency, called peso, which is issued by a domestic central bank. There is also a foreign currency called dollar. Foreign goods have a constant price of one in terms of dollars, so we speak indistinctly of dollars and foreign goods.

To finance operations, at the beginning of the period under study home firms borrow from the world market, here represented by a continuum of risk-neutral lenders. The key assumption in this section is that the typical firm can borrow or lend in pesos or dollars. Therefore, the firm's optimal borrowing policy determines the degree of "dollarization" in the economy, and will be influenced by the firm's expectations about equilibrium prices and the exchange rate. The latter are determined by the monetary policy chosen by the central bank, which in turn takes into account the degree of dollarization.

\section{$2.1 \quad$ Firms}

The representative firm has access to the technology

$$
Y=A K^{\alpha} L^{1-\alpha}
$$

where $0<\alpha<1$ and $A$ is a positive parameter. For simplicity, we also assume that the capital stock $K$ is of fixed size. Households are heterogeneous in the labor services they provide, and the input $L$ is an aggregate of the services of 
the different households in the economy:

$$
L=\left[\int_{0}^{1} L_{i}^{\frac{\theta-1}{\theta}} d i\right]^{\frac{\theta}{\theta-1}},
$$

where we have indexed workers by $i$ in the unit interval, $L_{i}$ denotes the services purchased from household $i$, and $\theta>1$ is the elasticity of demand for household $i$ 's services.

Let $W_{i}$ denote the wage charged by worker $i$ and $W$ denote the aggregate wage, that is, the minimum cost of a unit of the $L$ aggregate, expressed in terms of pesos. Cost minimization yields the demand for household $i^{\prime}$ s labor:

$$
L_{i}=\left(\frac{W_{i}}{W}\right)^{-\theta} L
$$

The firm has no capital to start with, so it must finance capital purchases by borrowing abroad. To do this, at the beginning of the period, the firm sells bonds denominated either in pesos $(B)$ or dollars $\left(B^{*}\right)$. A peso (resp. dollar) bond is a promise to a peso (resp. dollar) at the end of the period. Note that, in assuming that bond payments cannot be arbitrary functions of the state of nature, we are imposing market incompleteness, which implies that currency composition plays a nontrivial role.

We assume that the world interest rate in dollars is zero, so a dollar bond must sell for one dollar. Letting $Q$ denote the price in dollars of a peso bond, it follows that

$$
Q B+B^{*}=K,
$$

End of period firm profits, in dollars, are denoted by $\Pi$ and given by

$$
S \Pi=P Y-W L-S B^{*}-B,
$$

where $S$ is the exchange rate (in pesos per dollar) and $P$ the peso price of home output. As usual, we assume that $L$ is chosen at the end of the period, after uncertainty has been revealed.

Since the firm is owned by the representative household, it is natural to assume its objective function be $E\left\{u^{\prime}(C) \Pi\right\}$, where $u^{\prime}(C)$ is the marginal utility of the household's consumption, to be derived below, and $E\{$.$\} denotes the$ expectation at the beginning of the period. Hence the firm chooses $B, B^{*}$, and a contingent plan for $L$ so maximize $E\left\{u^{\prime}(C) \Pi\right\}$ subject to 2,3 , and 4 . The solution is

$$
E\left\{u^{\prime}(C)\left(Q-\frac{1}{S}\right)\right\}=0,
$$

and

$$
W L=(1-\alpha) P Y,
$$

which are standard. In particular, 5 characterizes the firm's optimal borrowing policy: issuing an additional unit of peso bonds costs $Q$ dollars at the beginning of the period, and requires a dollar repayment of $1 / S$ dollars at the end of the period. At the margin, the expected utility net gain from such issue must be zero. 


\subsection{Households}

As already mentioned, households provide differentiated labor services, so each household enjoys some monopoly power in the labor market. We assume that, at the beginning of the period, each household sets a wage in pesos, and commits to satisfy demand forthcoming at that wage at the end of the period. The household consumes the dollar value of its labor income plus firm profits.

Formally, household $i$ chooses its wage, $W_{i}$, to maximize

$$
E\left\{u\left(C_{i}\right)-\left(\frac{\theta-1}{\theta}\right) v\left(L_{i}\right)\right\}
$$

subject to

$$
S C_{i}=S \Pi+W_{i} L_{i}
$$

and to the labor demand function 2. The functions $u$ and $v$ satisfy usual assumptions, and $\theta>1$.

The optimal wage solves

$$
W E\left\{\frac{u^{\prime}(C) L}{S}\right\}=E\left\{L v^{\prime}(L)\right\},
$$

where we have imposed symmetry and eliminated $i$ subscripts.

\subsection{Foreign lenders}

Foreign lenders are risk neutral and only care about foreign goods. Hence they will buy peso bonds if and only if their expected return, in dollars, equals the dollar world return of zero. Therefore,

$$
Q=E\left\{\frac{1}{S}\right\}
$$

\subsection{Market clearing}

Since local residents do not consume home goods, the demand for home output comes from foreigners. We assume that the value of the foreign demand for home output is exogenous and given by a random variable $X$. We assume that $E(X)>K$ and that $X$ is the only source of uncertainty in the model. As a consequence, the demand function is simply given by

$$
P Y=S X .
$$

Competitive equilibrium is well defined once monetary policy is given. Before proceeding to the analysis of policy, note that in any competitive equilibrium household consumption is obtained by combining $3,4,7$, and 9

$$
C=\left(\frac{P}{S}\right) Y-\left(\frac{B}{S}+B^{*}\right)=X-K+\left(E\left\{\frac{1}{S}\right\}-\frac{1}{S}\right) B
$$


The first equality says that consumption equals the dollar value of output minus the cost of servicing the foreign debt. But 10 implies that, again in equilibrium, the dollar value of output is given by $X$, while the debt burden is equal to the initial cost of investment $(K)$ minus the capital gains or losses on peso debt associated with an exchange rate surprise (the last term on the RHS). So in this model the extent of debt dollarization cannot affect the expected value of consumption. Dollarization can affect the variability of consumption, but this depends on the distribution of the exchange rate and, hence, on policy.

\section{Equilibrium monetary policy}

We restrict attention to two policy alternatives: a fixed exchange rate, defined as a policy that keeps $S$ constant, and a flexible exchange rate, which keeps $P$ constant. This section studies the equilibrium outcomes, in particular the degree of dollarization, under either flexible rates and fixed rates. Then we ask whether either alternative is an equilibrium policy.

\subsection{Competitive equilibrium under a flexible exchange rate}

As mentioned earlier, flexible exchange rates are defined as a regime in which the price of home output is constant. The resulting outcomes will be denoted by tildes. Clearly the price level is immaterial, so we normalize $\tilde{P}=1$.

Equilibrium in the labor market (equation 6) reduces to

$$
\tilde{W} \tilde{L}=(1-\alpha) \tilde{Y}
$$

But by 1 output is a function only of $\tilde{L}$, and $\tilde{W}$ is set in advance. It follows that both $\tilde{Y}$ and $\tilde{L}$ must be constant under flexible rates. ${ }^{2}$ Intuitively, since monetary policy stabilizes the price of home output and nominal wages are preset, the real (product) wage is constant. Hence the marginal product of labor, labor demand, and output must be constant too.

The nominal exchange rate, however, is not constant. By 10,

$$
\tilde{S}=\frac{\tilde{Y}}{X}
$$

so the distribution of the exchange rate is given by the distribution of exports $X$. In particular, the nominal exchange rate appreciates when exports are higher.

What is the optimal portfolio allocation? Using 9 in the first-order condition 5 ,

$$
E\left\{u^{\prime}(\tilde{C})\left[E\left\{\frac{1}{\tilde{S}}\right\}-\frac{1}{\tilde{S}}\right]\right\}=0
$$

which implies

$$
\operatorname{Cov}\left\{\frac{1}{\tilde{S}}, u^{\prime}(\tilde{C})\right\}=0
$$

\footnotetext{
${ }^{2}$ Given $\tilde{W}, \tilde{Y}$ and $\tilde{L}$ are the solution of 1 and 12 .
} 
Equilibrium portfolios are such that the marginal utility of consumption is orthogonal to the terms of trade. The firm accomplished this by choosing $B$ and $B^{*}$ so as to make consumption constant. From 11 and the fact that under flexible exchange rates $\tilde{P}=1$, consumption is constant if

$$
\tilde{B}=\tilde{Y}
$$

which is therefore the optimal portfolio allocation. The intuition is straightforward. Given that labor effort is constant and so is the wage, the only risk the household faces is exchange rate risk, which can cause the price of domestic output in terms of consumption goods to fluctuate. The firm eliminates this risk on behalf of its owner, the household, by borrowing an amount in pesos equal to the (constant) value of output. This way the household is fully hedged against (real and nominal) exchange rate risk.

The corresponding constant consumption level is, by 11 and 13 ,

$$
\tilde{C}=E\{X\}-K \text {. }
$$

So, in equilibrium with flexible rates, the household consumes the expected dollar value of home output minus the cost of capital.

Note that under this allocation $\tilde{Q} \tilde{B}=\tilde{Y} E\{1 / \tilde{S}\}=E\{X\}>K$ is necessary for consumption to be positive. This means that initially the firm sells peso bonds with a higher value than its total foreign liability $K$, and devote some of the proceeds to buying dollar assets. So the firm becomes a net creditor in dollars and a net debtor in pesos. This ensures that capital gains obtain when the exchange rate depreciates, which are the exact circumstances in which the dollar value of national income is low.

To complete the characterization of the equilibrium, observe that nominal wages are given by the optimal wage setting condition 8 , which reduces to ${ }^{3}$

$$
\tilde{W}=\frac{v^{\prime}(\tilde{L})}{u^{\prime}(\tilde{C}) E\{1 / \tilde{S}\}}=\frac{v^{\prime}(\tilde{L}) \tilde{Y}}{u^{\prime}(\tilde{C}) E\{X\}} .
$$

\subsection{Is a flexible exchange rate an equilibrium policy?}

Suppose that for some reason agents expect a policy of floating and set wages and portfolios accordingly. Given those expectations, will the monetary authority deliver that policy ex-post? In other words, are expectations of floating selfvalidating? To answer these questions, here we consider whether floating is an equilibrium policy.

For the interaction between endogenous portfolio selection and monetary and exchange rate policy, the timing of moves is crucial. We assume the following: the period under analysis start with a contracting stage in which firms issue

\footnotetext{
${ }^{3}$ Note that this is not a closed form solution since $\tilde{L}$ and $\tilde{Y}$ depend on $\tilde{W}$. To obtain $\tilde{L}, \tilde{Y}$ and $\tilde{W}, 1,12$ and 14 must be solved simultaneously.
} 
bonds and workers set the value of their nominal wages. Then the central bank chooses the policy regime, either fixed or flexible exchange rates. The authorities take no other action after that. Finally, uncertainty about exports is realized and production, trade and consumption take place.

We assume that, in choosing the policy regime, the central bank maximizes the welfare of its representative citizen. Floating exchange rates are then an equilibrium policy if the central bank has no incentive to deviate for fixed exchange rates, given the portfolios and wage contracts were optimally written in the expectation of flexible rates. ${ }^{4}$

A general analysis of equilibrium policies turns out to be very complex. To simplify, we impose that, if the central bank is to deviate from flexible to fixed rates, the deviation must leave the expected dollar value of pesos unchanged at its pre-deviation level. This restriction is not only for tractability, but also to focus on domestic policy concerns and abstract from the (better known) time inconsistency issues associated with foreign debt: it ensures that a deviation implies no expected expropriation of foreign lenders. This may be justified by the existence of costs of international default.

Denote outcomes under a deviation to fixed exchange rates by an overbar. By assumption, after a policy deviation $1 / \bar{S}$ must equal $E\{1 / \tilde{S}\}$ which, given 13 , requires the exchange rate be fixed at

$$
\bar{S}=\frac{\tilde{Y}}{E(X)} .
$$

Also, 6 and 10 must hold, so labor effort is given by

$$
\bar{L}=\left(\frac{1-\alpha}{\tilde{W}}\right) \bar{S} X
$$

where the nominal wage rate is that associated with flexible rates, since it was set before the deviation. Using the definition of $\bar{S}$ from 15 in 16 we then obtain labor effort under a deviation:

$$
\bar{L}=\left(\frac{1-\alpha}{\tilde{W}}\right)\left(\frac{X}{E\{X\}}\right) \tilde{Y} .
$$

Hence labor effort becomes a linear function of $X$, with expectation

$$
E\{\bar{L}\}=\left(\frac{1-\alpha}{\tilde{W}}\right) \tilde{Y}=E\{\tilde{L}\} .
$$

In words, the deviation to fixed exchange rates keeps expected labor supply the same, but increases the variability of labor effort. The latter obtains because fixing the exchange rate means that the price of home output, and hence the real wage, must fluctuate in order to accommodate shocks to export demand.

\footnotetext{
${ }^{4}$ This definition of equilibrium policy is the same as in Chari and Kehoe (1990) and Stokey (1991).
} 
Using 11 and the fact that the deviation keeps $1 / \bar{S}$ at $E(1 / \tilde{S})$, consumption after a deviation to fixed rates is given by

$$
\bar{C}=X-K
$$

Taking expectations of this expression we again have that

$$
E\{\bar{C}\}=E\{X\}-K=\tilde{C}
$$

Hence, the deviation also causes a mean-preserving spread in consumption.

The analysis shows that, by deviating from flexible rates to fixed rates when households had expected the former, the monetary authority induces volatility into labor supply and consumption without changing the expected value of either variable. Since volatility decreases expected utility, the policymaker can only decrease expected utility by switching to fixed rates. It follows that flexible exchange rates are always an equilibrium policy regime.

\subsection{Competitive equilibrium under a fixed exchange rate}

Now consider a policy of fixing the exchange rate at $S=\bar{S}=1$ (we use overbars to denote fixed rates). Then nominal demand reduces to

$$
\bar{P} \bar{Y}=\bar{S} X=X
$$

and 6 gives labor effort:

$$
\bar{L}=\frac{(1-\alpha) X}{\bar{W}},
$$

So labor effort becomes proportional to the demand for home output. Employment must fluctuate since, with fixed exchange rates, the price of home output and the product wage must fluctuate to accommodate changes in demand.

Expression 11 for consumption becomes

$$
\bar{C}=X-K .
$$

Home consumption is equal to $X$ minus the constant value of investment. The reasons is clear from 11: since the exchange rate is fixed, home agents experience no unanticipated capital gains nor losses.

For the same reasons $B$ and $B^{*}$ are indeterminate, since bonds in pesos and dollars are now perfect substitutes. This means that portfolio composition may be pinned down by other things outside the model.

Finally, nominal wages are given by 8 , which reduces to

$$
\bar{W}=\frac{E\left\{\bar{L} v^{\prime}(\bar{L})\right\}}{E\left\{u^{\prime}(\bar{C}) \bar{L}\right\}}=\frac{E\left\{X v^{\prime}(\bar{L})\right\}}{E\left\{u^{\prime}(\bar{C}) X\right\}} .
$$




\subsection{Is a fixed exchange rate an equilibrium policy?}

To check whether a fixed rate is an equilibrium policy, consider a deviation to a flexible exchange rate, assuming that in such a deviation $E\{1 / \tilde{S}\}=1 / \bar{S}=1$. Again, the justification for the restriction is to ensure that the deviation imposes no expected expropriation on foreigners.

After a switch, 10 must hold, so that

$$
\frac{1}{\tilde{S}}=\frac{X}{\tilde{P} \tilde{Y}}
$$

By assumption, the expectation of the LHS after a deviation must equal unity. But the deviation also implies that both $\tilde{P}$ and $\tilde{Y}$ are constant. Hence, taking expectation on both sides of the preceding equation, and using 10 again, we find the exchange rate associated with the deviation,

$$
\tilde{S}=\frac{E\{X\}}{X} .
$$

Applying this to 6 we have that labor supply is given by

$$
\tilde{L}=\frac{(1-\alpha) \tilde{S} X}{\bar{W}}=\frac{(1-\alpha) E\{X\}}{\bar{W}} .
$$

Comparing this last expression with 18 we see that after a deviation to floating labor effort is no longer variable, and its mean value does not change. Hence there is a "temptation" to abandon fixed rates.

To find the effect on consumption of a switch to flexible rates, use 21 in 11 evaluated at $E\{1 / \tilde{S}\}=1$. This yields

$$
\tilde{C}=X\left(1-\frac{\bar{B}}{E\{X\}}\right)+\bar{B}-K .
$$

Hence the effect of the deviation on consumption depends on the degree of dollarization, which is indeterminate under fixed rates. But notice that $E\{\tilde{C}\}=$ $E\{X\}-K$, so the deviation keeps the expected value of consumption constant. Therefore, expected utility from consumption may increase or fall depending on the response of the variability of consumption to the deviation.

From 22 we see that after a deviation the variance of consumption must fall if $0<B<2 E\{X\}$, and it must increase otherwise. If the variance falls, the policymaker will unambiguously want to deviate, since that would reduce the variance of both consumption and labor supply while preserving their expected values. For instance, if (by fluke) agents had adopted the portfolio that corresponds to the expectation of flexible rates, the variance of consumption after the switch would fall to zero, and deviating from fixed rates would be optimal for the policymaker.

It follows that a necessary condition for fixed rates to an equilibrium policy is either $B<0$ or $B>2 E\{X\}$. The first case is perhaps the more interesting 
one: the representative agent has gross assets in pesos and gross debts in dollars. In equilibrium, this currency mismatch makes no difference to him nor to lenders. But it deters the government from abandoning fixed exchange rates. Dollarization of liabilities gives rise to fear of floating.

Summarizing: if is either $B<0$ or $B>2 E\{X\}$, the switch to flexible rates induces a mean-preserving spread on consumption relative to fixed exchange rates. Since the deviation keeps labor effort at its mean value under fixed rates, fixed exchange rates may or may not be an equilibrium. This depends on the parameters of the model and, in particular, on the utility cost associated with consumption fluctuations relative to labor effort fluctuations (determined by the shape and curvature of $u$ and $v$ ). But also, and importantly for our purposes, it depends on the currency composition of the firm's debt, which is not uniquely pinned down in equilibrium.

If a fixed exchange rate is in fact an equilibrium, then there are multiple equilibria in policy regimes, since flexible exchange rates are always an equilibrium. In that case, animal spirits play a role: if agents expect fixed rates (and $B<0$ or $B>2 E\{X\})$ the government will indeed deliver fixed rates; if agents expect flexible rates, the government will choose flexible rates.

Example: Suppose

$$
u(C)=\frac{C^{1-\rho}}{1-\rho}
$$

and

$$
v(L)=\frac{\kappa}{2} L^{2}
$$

The equilibrium wage is then given by inserting 19 and 18 in 20 :

$$
\bar{W}^{2}=\frac{\kappa(1-\alpha) E\left\{X^{2}\right\}}{E\{X\}(X-K)^{-\rho}}
$$

One can then calculate that switching from fixed rates to fixed rates increases the expected cost of labor effort by

$$
E\{v(\bar{L})\}-E\{v(\tilde{L})\}=\frac{(1-\alpha)}{2}\left(E(X)(X-K)^{-\rho}\right) \frac{\operatorname{Var}(X)}{E\left\{X^{2}\right\}}>0
$$

The switch also causes an expected change in the utility of consumption of

$E\{u(\bar{C})\}-E\{u(\tilde{C})\}=\frac{1}{1-\rho}\left[E\left\{(X-K)^{1-\rho}\right\}-E\left\{X-K+B\left(1-\frac{X}{E(X)}\right)\right\}\right]^{1-\rho}$

The arguments above imply that $E\{u(\bar{C})\}-E\{u(\tilde{C})\}>0$ if $B<0$ or $B>2 E\{X\}$. Assuming that either condition holds, fixed exchange rates are an equilibrium policy if

$$
E\{u(\bar{C})\}-E\{u(\tilde{C})\}-\left(\frac{\theta-1}{\theta}\right)[E\{v(\bar{L})\}-E\{v(\tilde{L})\}]>0 .
$$

For any given $\bar{B}$, this condition is satisfied if either $\theta$ or $\alpha$ are close enough to one. 


\subsection{Welfare}

Our analysis implies that both flexible rates and fixed exchange rates can be equilibrium policies in our model. Importantly, they can also be Pareto ranked when they coexist.

We have already shown that expected consumption must be the same under both policy regimes, and that flexible exchange rates completely stabilize both consumption and labor effort. However, it is hard to compare the mean value of labor effort under the two regimes. Hence the welfare ranking may depend on functional forms and parameter values.

However, there is no ambiguity if utility functions are CRRA or quadratic: flexible rates perform better. To see this formally, assume first that preferences are of the form

$$
E\left\{\frac{C^{1-\rho}}{1-\rho}-\left(\frac{\theta-1}{\theta}\right) \frac{L^{1+\chi}}{1+\chi}\right\}, \rho>0, \chi>0 .
$$

Under floating, 14 and 12 yield

$$
\tilde{L}^{1+\chi}=(1-\alpha) u^{\prime}(E\{X\}-K) E\{X\},
$$

where we have used the fact that with the assumed utility function $L v^{\prime}(L)=$ $L^{1+\chi}$, and also the fact that under floating $\tilde{C}=E\{X\}-K$. Using 24 in 23 yields

$$
E\left\{U^{\mathrm{flex}}\right\}=\psi \frac{(E\{X\}-K)^{1-\rho}}{1-\rho}-(1-\psi) \frac{K(E\{X\}-K)^{-\rho}}{1-\rho}
$$

where $\psi \equiv 1-(1-\rho)\left(\frac{1-\alpha}{1+\chi}\right)\left(\frac{\theta-1}{\theta}\right)>0$.

With analogous steps one can derive an expression for expected utility under fixing, which is

$$
E\left\{U^{\mathrm{fix}}\right\}=\psi \frac{E\left\{(X-K)^{1-\rho}\right\}}{1-\rho}-(1-\psi) \frac{K E\left\{(X-K)^{-\rho}\right\}}{1-\rho} .
$$

Comparing 25 and 26 we see that $E U^{\text {flex }}>E U^{f i x}$. The appendix analyzes the case in which both $u(C)$ and $v(L)$ are quadratic, and shows that $E\left\{U^{\text {flex }}\right\}>E\left\{U^{\text {fix }}\right\}$ also.

We conclude that for two broadly used classes of preferences, the regime with flexible exchange rates yields higher expected welfare. In those cases, if both flexible and fixed rates are equilibrium policy regimes, benevolent policymakers must endeavor to convince agents that floating will indeed be the chosen policy. One alternative is to commit to a flexible regime. If this is not possible, direct regulation of portfolios so as to make flexible rates optimal ex post could also be desirable. Recent attempts at "de-dollarizing" financial contracts may be justified, then, as coordination devices. 


\section{Indexed bonds}

Readers might wonder whether the results on the multiplicity of equilibrium policy regimes are an artifice of the indeterminacy of portfolios under fixed rates. That is not so, as we show in this section by extending the model to a menu of assets that ensures that portfolios are always fully determined.

We replace peso bonds with bonds that have payoffs indexed to the price of the domestic good. Such bonds are common in emerging markets. More precisely, we assume that the representative firm sells dollar bonds and indexed bonds. An indexed bond is a promise to $P$ pesos at the end of the period.

Rather than developing the model from scratch, we simply write down the equilibrium conditions that differ from those of the earlier formulation. Foreign lenders again arbitrage the returns on both kinds of loans, so the initial price of an indexed bond, in dollars, must equal the expected terms of trade $E\{P / S\}$.

The optimal wage setting condition 8 remains the same, while the optimal portfolio condition 5 becomes

$$
E\left\{u^{\prime}(C)\left(E\left\{\frac{P}{S}\right\}-\frac{P}{S}\right)\right\}=0,
$$

Market clearing is still given by 10 , while expression 11 for consumption becomes

$$
C=X-K+B\left(E\left\{\frac{P}{S}\right\}-\frac{P}{S}\right)
$$

where $B$ now denotes the outstanding number of indexed bonds.

\subsection{A flexible exchange rate once again}

Consider first a flexible rates regime with $\tilde{P}=1$. Assuming that this policy is credible and indeed carried out, indexed bonds become identical to peso bonds. Hence the outcomes are just the same as with flexible exchange rates in the model with peso bonds, characterized in subsection 3.1. Notice in particular that $\tilde{B}=\tilde{Y}$, that is, indexed bonds in the portfolio are equal to the value of home output.

Indexed bonds do make a difference, however, in analyzing whether flexible rates are an equilibrium policy regime. Consider the implications of a deviation towards fixed exchange rates. Again to prevent expected expropriation of foreign lenders, we assume that such a deviation leaves the expected terms of trade, $P / S$, unchanged. Using overbars once more to denote the consequences of a deviation to fixed rates, this requires

$$
E\left\{\frac{\bar{P}}{\bar{S}}\right\}=E\left\{\frac{1}{\tilde{S}}\right\}=\frac{E\{X\}}{\tilde{Y}},
$$

where the last equality follows from 10 .

To solve for the consequences of a deviation, note that 6 implies

$$
\bar{L}=\frac{(1-\alpha) \bar{S} X}{\tilde{W}} .
$$


Moreover, from 10, we have

$$
\bar{P}=\frac{\bar{S} X}{\bar{Y}}=\frac{\bar{S} X}{A K^{\alpha} \bar{L}^{1-\alpha}}=\left(\frac{\bar{S} X}{\tilde{Y}}\right)^{\alpha},
$$

where the last equality follows from 30,1 and 12 . It follows that

$$
\frac{\bar{P}}{\bar{S}}=\left(\frac{X}{\tilde{Y}}\right)^{\alpha} \bar{S}^{\alpha-1}
$$

Taking expectations and using 29 one obtains the nominal exchange rate under a feasible deviation:

$$
\bar{S}=\tilde{Y}\left(\frac{E\left\{X^{\alpha}\right\}}{E\{X\}}\right)^{\frac{1}{1-\alpha}} .
$$

Inserting this value in 31 and simplifying one gets the price level after a deviation:

$$
\bar{P}=X^{\alpha}\left(\frac{E\left\{X^{\alpha}\right\}}{E\{X\}}\right)^{\frac{\alpha}{1-\alpha}} .
$$

So, in particular,

$$
E\{\bar{P}\}=\left(\frac{E\left\{X^{\alpha}\right\}}{[E\{X\}]^{\alpha}}\right)^{\frac{1}{1-\alpha}}<1 .
$$

Hence a switch from flexible rates to fixed rates implies a fall in the expected price of home output. It follows that the expected real wage rises, and expected labor effort falls. Formally, from 30,32 and the definition of $\tilde{Y}$ one can derive

$$
\bar{L}=\tilde{L} \frac{X}{E\{X\}} E\{\bar{P}\} .
$$

Taking expectations we have

$$
E\{\bar{L}\}=\tilde{L} E\{\bar{P}\}<\tilde{L} .
$$

Hence, the deviation to fixed rates implies that labor effort becomes variable but, in contrast with the case of peso bonds, the mean value of labor effort falls. The reduction in mean labor effort is welfare-improving, making a switch towards fixed rates attractive. ${ }^{5}$

As in the case of peso bonds, the switch from flexible to fixed exchange rates causes a mean-preserving spread in consumption (the proof is similar to the one in the case of peso bonds and left to the interested reader.) Additional consumption variability makes expected welfare fall and reduces the desirability of the deviation, as in the case of peso bonds. However, with indexed bonds,

\footnotetext{
${ }^{5}$ The fact that an increase in labor supply is welfare-decreasing might seem surprising, since the model features imperfect competition in the labor market, which causes equilibrium labor supply to be too low relative to the planner's solution. But in this model the dollar value of domestic production is given by 10 . Hence working more just causes the terms of trade to turn against the country, without any benefit for consumption.
} 
mean labor effort falls. Flexible rates are an equilibrium if the utility benefit associated with the smaller labor effort is less than the cost associated with increased variability in both consumption and labor.

As a special case, assume that

$$
v(L)=\phi L^{1+\chi}
$$

where $\phi>0$ is an arbitrary constant and $\chi>0$. Assume also that $X$ is lognormally distributed. Then, as we show in the appendix, the sign of $E\{v(\bar{L})\}-v(\tilde{L})$ equals the sign of $\chi-\alpha$. A switch from flexible rates to fixed rates increases or leaves the same the expected cost of effort if $\chi \geq \alpha$. Since the switch always causes a mean-preserving spread in consumption, then $\chi \geq \alpha$ is sufficient for the switch to be welfare-decreasing -that is, for flexible rates to be an equilibrium policy.

The intuition is that the larger is $\chi$, the larger is the utility cost of the increased variability of labor effort under a deviation. On the other hand, by 30 , a larger $\alpha$ results in smaller fluctuations in labor effort in a deviation. So the cost of a switch from a flexible to a fixed exchange rate increases with $\chi$ and falls with $\alpha$.

\subsection{A fixed exchange rate once again}

Consider next the policy of fixing the exchange rate at $\bar{S}=1$. Condition 18 still gives labor effort, and 28 implies that

$$
\bar{C}=X-K+\bar{B}(E\{\bar{P}\}-\bar{P})
$$

This expression shows that, in contrast with the case of nominal peso bonds, the currency composition of the debt matters here even with fixed exchange

rates. The central bank can peg the nominal exchange rate but not the terms of trade; if peso bonds are indexed, capital gains and losses depend on the latter.

As a consequence, $\bar{B}$ is not indeterminate. Instead, it must be set to satisfy the condition 27 , which here reduces to

$$
\operatorname{Cov}\left(u^{\prime}(\bar{C}), \bar{P}\right)=0
$$

The price of home output follows from 17 and the production function:

$$
\bar{P}=\frac{X}{\bar{Y}}=\frac{X^{\alpha}}{A K^{\alpha}}\left(\frac{\bar{W}}{1-\alpha}\right)^{1-\alpha} .
$$

The rest of the analysis turns out to be more difficult than before, so we assume from now on that $u(C)$ is quadratic (at least in the relevant range). Then $u^{\prime}$ is linear in $C$, and the previous expression reduces to

$$
\operatorname{Cov}(\bar{C}, \bar{P})=0
$$


That is, equilibrium portfolios must be set so that consumption is orthogonal to the terms of trade. Using the previous expression for $\bar{C}$ one readily finds that the stock of indexed bonds in the equilibrium portfolio is

$$
\bar{B}=\frac{\operatorname{Cov}(X, \bar{P})}{\operatorname{Var}(\bar{P})}
$$

This is intuitive: with quadratic utility, $\bar{B}$ must be chosen to minimize the variance of consumption which, from 36 , is the variance of $X-\bar{B} \bar{P}$. Hence $\bar{B}$ is the coefficient of a linear regression of $X$ on $\bar{P}$.

Given 37 the preceding expression can be written as

$$
\bar{B}=\frac{\operatorname{Cov}\left(X, X^{\alpha}\right)}{\operatorname{Var}\left(X^{\alpha}\right)} A K^{\alpha}\left(\frac{1-\alpha}{\bar{W}}\right)^{1-\alpha} .
$$

Replacing 38 in 36 yields equilibrium consumption:

$$
\bar{C}=X-K+\frac{\operatorname{Cov}\left(X, X^{\alpha}\right)}{\operatorname{Var}\left(X^{\alpha}\right)}\left[E\left\{X^{\alpha}\right\}-X^{\alpha}\right]
$$

Now consider a deviation to flexible rates, imposing once more the restriction of no expropriation to foreign lenders, which requires that the post-deviation expected value $E\{\tilde{P} / \tilde{S}\}$ must equal $E\{\bar{P}\}$.

After the deviation, 6 must hold, which together with the production function yields labor effort:

$$
\tilde{L}=A^{\frac{1}{\alpha}} K\left(\frac{1-\alpha}{\bar{W}}\right) \tilde{P}^{\frac{1}{\alpha}}
$$

where $\tilde{P}$ is the price level after the deviation, to be determined shortly.

Since 10 must hold, $\tilde{P} / \tilde{S}=X / \tilde{Y}$. Taking expectations on both sides and using the production function and 40 one obtains

$$
E\left\{\frac{\tilde{P}}{\tilde{S}}\right\}=\frac{E\{X\}}{K A^{\frac{1}{\alpha}}}\left(\frac{(1-\alpha) \tilde{P}}{\bar{W}}\right)^{-\frac{1-\alpha}{\alpha}} .
$$

But this has to be equal to $E\{\bar{P}\}$, where $\bar{P}$ is given by 37 . So, taking expectations in 37 , equating the result to the preceding equation and rearranging gives the required value of $\tilde{P}$ :

$$
\tilde{P}=\left(\frac{E\{X\}}{E\left\{X^{\alpha}\right\}}\right)^{\frac{\alpha}{1-\alpha}} \frac{1}{A K^{\alpha}}\left(\frac{\bar{W}}{1-\alpha}\right)^{1-\alpha} .
$$

Replacing in the equation for $\tilde{L}$ above we obtain

$$
\tilde{L}=\left(\frac{(E\{X\})^{\alpha}}{E\left\{X^{\alpha}\right\}}\right)^{\frac{1}{1-\alpha}}\left(\frac{1-\alpha}{\bar{W}}\right) E\{X\}>\left(\frac{1-\alpha}{\bar{W}}\right) E\{X\}=E\{\bar{L}\} .
$$


The inequality follows from Jensen's inequality. Switching to flexible rates stabilizes labor effort, but at a level that is higher than the mean value of $L$ under fixed rates. The sum of these two effects on the representative household's welfare is ambiguous and depends on the parameters of the model.

The effect of the deviation on consumption can be calculated from

$$
\tilde{C}=X-K+\bar{B}\left(E \bar{P}-\frac{\tilde{P}}{\tilde{S}}\right) .
$$

Using 10 once more and after some tedious algebra one obtains

$$
\tilde{C}=X-K+\frac{\operatorname{Cov}\left(X, X^{\alpha}\right)}{\operatorname{Var}\left(X^{\alpha}\right)} \frac{E\left\{X^{\alpha}\right\}}{E\{X\}}[E\{X\}-X] .
$$

Recalling 39, one readily notices that $E\{\bar{C}\}=E\{\tilde{C}\}$ : the deviation leaves the expected value of consumption unchanged. But the effect on consumption variance is unclear, although the expressions for $\bar{C}$ and $\tilde{C}$ reveal that it depends solely on $\alpha$ and the distribution of $X$.

\subsection{Multiplicity of policy regimes: a special case}

When are a fixed and a flexible exchange rate both equilibrium policy regimes? We can identify precise conditions for this to happen if $X$ is lognormal and $v$ is of the form 35, which we assume from now on. Then, as the appendix shows, a switch from fixed rates to flexible rates must increase the variance of consumption. The appendix also shows that the switch increases the expected cost of effort if $\alpha>\chi$, leaves it the same if $\alpha=\chi$, and reduces it otherwise. As a consequence, $\alpha \geq \chi$ is sufficient (not necessary) for fixed rates to an equilibrium policy.

Recall from the discussion at the end of the last subsection that $\chi \geq \alpha$ is also sufficient for flexible rates to be an equilibrium policy. It follows that both flexible rates and fixed rates are equilibrium outcomes if $\alpha$ and $\chi$ are sufficiently close to each other. Hence, the fact that peso bonds are indexed does not eliminate the possibility of multiple equilibria in this model.

If both flexible rates and fixed rates are equilibrium outcomes, the appendix shows that $\bar{B}^{*}$ is larger than $\tilde{B}^{*}$ in absolute value. That is, under fixed rates the firm issues more indexed debt and purchases more dollar assets than under flexible rates. Why? The intuition is as follows. Flexible exchange rates stabilize the price of home output, the real wage, and therefore labor effort. The home portfolio is then structured to eliminate fluctuations in consumption.

With fixed exchange rates, by contrast, the price of home output and labor employment fluctuate. An adverse shock to exports $X$, for example, lowers $\tilde{P}$ and $\tilde{L}$ and increases leisure. Portfolios are structured $e x$ ante so that when leisure rises, consumption rises too. The firm accomplishes this by issuing more indexed debt than under flexible rates, so that there is a bigger capital gain when $\tilde{P}$ falls and the real exchange rate depreciates. 
Finally, the appendix shows that if both fixed and flexible exchange rates are equilibria, flexible rates again yields higher welfare. In such a case, fixed exchange rates may occur as a coordination failure: if agents expect fixing and arrange their portfolios accordingly, the monetary authority will validate those expectations, and social welfare will be inefficiently low. As in the case with peso bonds, enabling the monetary authority to commit to a policy of flexible rates would raise social welfare. Alternatively, direct controls on portfolio shares could also be welfare-improving.

\section{Final remarks}

We have built a model in which both portfolio composition and monetary policies are determined optimally. A key implication is that, since optimal portfolios depend on policy and viceversa, there may be more than one equilibrium policy regime. This suggests that the fear of floating that allegedly obtains in many countries may be an artifact of arbitrary expectations. For certain parameter values and shock distributions, expectations may be self-validating: if agents expect fixing and arrange their portfolios accordingly, the monetary authority will indeed deliver a fixed exchange rate. What the literature on fear of floating fails to take into account is that the same would happen if agents expected a policy of flexible exchange rates: assets and liabilities would be denominated in such a way as to make floating optimal for the authorities.

Which equilibrium the economy lands on matters. We are able to show that for plausible functional forms and lognormality of the shock, flexing delivers higher expected social welfare than does fixing. Therefore, policies that anchor expectations on the flexible rates outcome -or, alternatively, induce agents to hold a portfolio that is compatible with flexing- raise social welfare.

One limitation of the analysis is that here portfolio composition is endogenous, but only given the exogenous restrictions on the menu of assets. While we have allowed for an asset menu that included more than the usual noncontingent world currency bonds, it may be desirable and useful to derive market incompleteness from more fundamental assumptions on the environment. That remains a substantial task, however, and at this point we can only leave it for future research.

A second limitation, of course, is that we have imposed strong restrictions on the environment and policy options. These restrictions were justified on the basis of tractability and analytical convenience, but obviously they will have to be relaxed if the model is to be the basis for more realistic policy evaluation. 


\section{A Appendix}

Proof of claims at the end of section 3. Assume preferences are such that

$$
E\left\{-\frac{1}{2}\left(C-C^{*}\right)^{2}-\frac{1}{2}\left(\frac{\theta-1}{\theta}\right) L^{2}\right\} .
$$

Then, under flexible rates, 24 in the text is

$$
\tilde{L} v^{\prime}(\tilde{L})=\tilde{L}^{2}=(1-\alpha)\left(C^{*}-E\{X\}+K\right) E\{X\},
$$

where we have used the fact that $\tilde{C}=E\{X\}-K$. Plugging 44 into 43 , expected utility becomes

$$
E\left\{U^{\text {flex }}\right\}=\kappa\left(C^{*}-E\{X\}+K\right) E\{X\}-\Gamma
$$

where $\kappa=\frac{1}{2}\left[1-(1-\alpha)\left(\frac{\theta-1}{\theta}\right)\right]>0$ and $\Gamma=\frac{1}{2}\left(C^{*}-E\{X\}+K\right)\left(C^{*}+K\right)>$ 0 .

Under fixing, given that $\bar{C}=X-K$, wage setting equation 20 in the text can be written as

$$
E \bar{L}^{2}=(1-\alpha) E\left\{\left(C^{*}-X+K\right) X\right\} .
$$

Using this in the utility function 43 yields

$$
E\left\{U^{\mathrm{fix}}\right\}=\kappa E\left\{\left(C^{*}-X+K\right) X\right\}-\Gamma .
$$

Comparing 45 and 46 we see that $E U^{f l e x}>E U^{\text {fix }}$ requires

$$
\left(C^{*}-E\{X\}+K\right) E\{X\}>E\left\{\left(C^{*}-X+K\right) X\right\}
$$

or

$$
(E\{X\})^{2}<E\left\{X^{2}\right\}
$$

which always holds for non-degenerate $X$.

Proof of claim at the end of subsection 4.1. A switch from flex to fix implies an expected cost of labor effort of

$$
\begin{aligned}
& E v(\bar{L})=\phi E \bar{L}^{1+\chi} \\
= & \phi E\left[\tilde{L} \frac{X}{E\{X\}} E\{\bar{P}\}\right]^{1+\chi} \text { by } 34 \\
= & \phi \tilde{L}^{1+\chi}\left[\frac{E\{\bar{P}\}}{E\{X\}}\right]^{1+\chi} E\left\{X^{1+\chi}\right\} \\
= & v(\tilde{L})\left(\frac{E\left\{X^{\alpha}\right\}}{(E X)^{\alpha}}\right)^{\frac{1+\chi}{1-\alpha}}(E X)^{-(1+\chi)} E\left\{X^{1+\chi}\right\} \text { by } 33 .
\end{aligned}
$$

Therefore, 


$$
E\{v(\bar{L})\}=v(\tilde{L}) E\left\{X^{1+\chi}\right\}\left(E\left\{X^{\alpha}\right\}\right)^{\frac{1+\chi}{1-\alpha}}(E\{X\})^{-\frac{1+\chi}{1-\alpha}}
$$

Divide both sides of the last equation by $v(\tilde{L})$ and take logs:

$$
\begin{aligned}
& \log \left[\frac{E\{v(\bar{L})\}}{v(\tilde{L})}\right]=\log E\left\{X^{1+\chi}\right\}+\frac{1+\chi}{1-\alpha} \log \left[E\left\{X^{\alpha}\right\}\right]-\frac{1+\chi}{1-\alpha} \log E\{X\} \\
= & {\left[(1+\chi) \mu+(1+\chi)^{2} \frac{\sigma^{2}}{2}\right]+\frac{1+\chi}{1-\alpha}\left(\alpha \mu+\alpha^{2} \frac{\sigma^{2}}{2}\right)-\frac{1+\chi}{1-\alpha}\left(\mu+\frac{\sigma^{2}}{2}\right) } \\
= & \frac{1+\chi}{1-\alpha}\left[(1-\alpha)\left(\mu+(1+\chi) \frac{\sigma^{2}}{2}\right)+\left(\alpha \mu+\alpha^{2} \frac{\sigma^{2}}{2}\right)-\left(\mu+\frac{\sigma^{2}}{2}\right)\right] \\
= & \frac{1+\chi}{1-\alpha} \frac{\sigma^{2}}{2}\left[(1-\alpha)(1+\chi)-\left(1-\alpha^{2}\right)\right]=(1+\chi) \frac{\sigma^{2}}{2}(\chi-\alpha)
\end{aligned}
$$

where from the second equality on we have assumed that $\log X$ is normal with mean $\mu$ and variance $\sigma^{2}$. The claim follows.

Proof of claims at the end of subsection 4.2. Recall that with fixed rates, consumption is given by (39), so its variance is:

$$
\begin{aligned}
\operatorname{Var} \bar{C} & =\operatorname{Var}\left[X-\frac{\operatorname{Cov}\left(X, X^{\alpha}\right)}{\operatorname{Var} X^{\alpha}} X^{\alpha}\right] \\
& =\operatorname{Var}(X)\left[1-\frac{\operatorname{Cov}^{2}\left(X, X^{\alpha}\right)}{(\operatorname{Var} X)\left(\operatorname{Var} X^{\alpha}\right)}\right]
\end{aligned}
$$

A switch to flexible rates implies that consumption is given by (42), with variance:

$$
\operatorname{Var} \tilde{C}=\left[1-\frac{\operatorname{Cov}\left(X, X^{\alpha}\right)}{\operatorname{Var}\left(X^{\alpha}\right)} \frac{E\left\{X^{\alpha}\right\}}{E\{X\}}\right]^{2} \operatorname{Var}(X)
$$

Hence the sign of $\operatorname{Var} \tilde{C}-\operatorname{Var} \bar{C}$ equals the sign of

$$
\left[1-\frac{\operatorname{Cov}\left(X, X^{\alpha}\right)}{\operatorname{Var}\left(X^{\alpha}\right)} \frac{E\left\{X^{\alpha}\right\}}{E\{X\}}\right]^{2}-\left[1-\frac{\operatorname{Cov}^{2}\left(X, X^{\alpha}\right)}{(\operatorname{Var} X)\left(\operatorname{Var} X^{\alpha}\right)}\right]
$$

Assume again that $\log X \sim N\left(\mu, \sigma^{2}\right)$. Then,

$$
E X^{\alpha}=E e^{\alpha \log X}=e^{\mu+\sigma^{2} / 2}
$$

and so on. Some very tedious algebra then gives:

$$
\frac{\operatorname{Cov}\left(X, X^{\alpha}\right)}{\operatorname{Var}\left(X^{\alpha}\right)} \frac{E\left\{X^{\alpha}\right\}}{E\{X\}}=\frac{e^{\alpha \sigma^{2}}-1}{e^{\alpha^{2} \sigma^{2}}-1}
$$

and

$$
\frac{\operatorname{Cov}^{2}\left(X, X^{\alpha}\right)}{(\operatorname{Var} X)\left(\operatorname{Var} X^{\alpha}\right)}=\frac{\left(e^{\alpha \sigma^{2}}-1\right)^{2}}{\left(e^{\alpha^{2} \sigma^{2}}-1\right)\left(e^{\sigma^{2}}-1\right)}
$$


Change variables and define $z=e^{\sigma^{2}}$. Note that $z$ depends on $\sigma^{2}$, the variance of $\log X$, and is always greater than one. Replacing in 47 and simplifying one finds that the sign of $\operatorname{Var} \tilde{C}-\operatorname{Var} \bar{C}$ is given by the sign of

$$
z^{1+\alpha}+z^{\alpha(1+\alpha)}+z+z^{\alpha^{2}}-2 z^{\alpha}-2 z^{1+\alpha^{2}}
$$

We have not been able to find the sign of this polynomial analytically, but a graph of the above expression for $\alpha$ in $[0,1]$ and $z>1$ makes it obvious that the sign is positive. It follows that a switch from fix to flex increases the variance of consumption.

To find the effect of the switch on the expected cost of effort, note that under fixed rates labor effort is given by:

$$
\bar{L}=\frac{(1-\alpha) X}{\bar{W}}
$$

while 41 says that a switch stabilizes labor effort at

$$
\tilde{L}=\left[\frac{(E\{X\})^{\alpha}}{E\left\{X^{\alpha}\right\}}\right]^{\frac{1}{1-\alpha}}\left(\frac{1-\alpha}{\bar{W}}\right) E\{X\} .
$$

Assuming 35 and replacing in the above one finds that:

$$
\frac{v(\tilde{L})}{E\{v(\bar{L})\}}=\frac{(E\{X\})^{1+\chi}}{E\left\{X^{1+\chi}\right\}}\left[\frac{(E\{X\})^{\alpha}}{E\left\{X^{\alpha}\right\}}\right]^{\frac{1+\chi}{1-\alpha}} .
$$

If $\log X \sim N\left(\mu, \sigma^{2}\right)$, after taking logs the preceding expression simplifies further to:

$$
\log \left(\frac{v(\tilde{L})}{E\{v(\bar{L})\}}\right)=(1+\chi)(\alpha-\chi) .
$$

So the sign of $v(\tilde{L})-E\{v(\bar{L})\}$ is equal to the sign of $(\alpha-\chi)$, as claimed in the text.

Now assume both fix and flex are equilibria and turn to the comparison of $\tilde{B}^{*}$ and $\bar{B}^{*}$. Clearly,

$$
\begin{aligned}
\tilde{B}^{*} & =K-E\{1 / \tilde{S}\} \tilde{B} \\
& =K-E\{1 / \tilde{S}\} \tilde{Y}=K-E\{X\}
\end{aligned}
$$

while

$$
\begin{aligned}
\bar{B}^{*} & =K-E\{\bar{P}\} \tilde{B} \\
& =K-E\{\bar{P}\} \frac{\operatorname{Cov}(X, \bar{P})}{\operatorname{Var} \bar{P}} \\
& =K-\frac{\operatorname{Cov}\left(X, X^{\alpha}\right)}{\operatorname{Var}\left(X^{\alpha}\right)} E\left\{X^{\alpha}\right\}
\end{aligned}
$$


Hence

$$
\begin{aligned}
\tilde{B}^{*}-\bar{B}^{*} & =\frac{\operatorname{Cov}\left(X, X^{\alpha}\right)}{\operatorname{Var}\left(X^{\alpha}\right)} E\left\{X^{\alpha}\right\}-E\{X\} \\
& =E\{X\}\left[\frac{\operatorname{Cov}\left(X, X^{\alpha}\right)}{\operatorname{Var}\left(X^{\alpha}\right)} \frac{E\left\{X^{\alpha}\right\}}{E\{X\}}-1\right] \\
& =E\{X\}\left[\frac{e^{\alpha \sigma^{2}}-1}{e^{\alpha^{2} \sigma^{2}}-1}-1\right]>0
\end{aligned}
$$

where the third equality follows from 48. So $\bar{B}^{*}<\tilde{B}^{*}<0$. as claimed in the text.

Finally, with quadratic utility, the same arguments as with nominal bonds imply that

$$
(1-\alpha) E\left\{u^{\prime}(C) X\right\}=E\left\{L^{2}\right\}
$$

under both flex and fix.

Then, utility under flex is

$$
E\left\{U^{\text {flex }}\right\}=-\frac{1}{2}\left(C^{*}-\tilde{C}\right)^{2}-\frac{(1-\alpha)}{2}\left(\frac{\theta-1}{\theta}\right)\left(C^{*}-\tilde{C}\right) E\{X\},
$$

while that under fix we have:

$$
E\left\{U^{f i x}\right\}=-\frac{1}{2} E\left\{\left(C^{*}-\bar{C}\right)^{2}\right\}-\frac{(1-\alpha)}{2}\left(\frac{\theta-1}{\theta}\right) E\left\{\left(C^{*}-\bar{C}\right) X\right\}
$$

But note that under fixed rates

$$
\bar{C}=X-K+\bar{B}\left(E\left\{X^{\alpha}\right\}-X^{\alpha}\right)=\tilde{C}+\Omega,
$$

where

$$
\Omega \equiv \bar{B}\left(E\left\{X^{\alpha}\right\}-X^{\alpha}\right)+(X-E\{X\})
$$

and clearly $E\{\Omega\}=0$. Replacing in 49 above yields:

$$
\begin{aligned}
E\left\{U^{f i x}\right\} & =-\frac{1}{2} E\left\{\left(C^{*}-\tilde{C}-\Omega\right)^{2}\right\}-\frac{(1-\alpha)}{2}\left(\frac{\theta-1}{\theta}\right) E\left\{\left(C^{*}-\tilde{C}-\Omega\right) X\right\} \\
& =E\left\{U^{\text {flex }}\right\}-\frac{1}{2} E\left\{\Omega^{2}\right\}+\frac{(1-\alpha)}{2}\left(\frac{\theta-1}{\theta}\right) E\{\Omega X\}
\end{aligned}
$$

So the sign of $E\left\{U^{f i x}\right\}-E\left\{U^{f i x}\right\}$ is the sign of

$$
E\left\{\Omega^{2}\right\}-(1-\alpha)\left(\frac{\theta-1}{\theta}\right) E\{\Omega X\}
$$

Now recall $\bar{B}=\frac{\operatorname{Cov}\left(X^{\alpha}, X\right)}{\operatorname{Var} X^{\alpha}}$. Using this one can show that

$$
E\left\{\Omega^{2}\right\}=E\{\Omega X\},
$$

so expression 50 reduces to

$$
\left(1-(1-\alpha)\left(\frac{\theta-1}{\theta}\right)\right) E\left\{\Omega^{2}\right\}>0 .
$$

We conclude that flexing delivers higher expected welfare than fixing. 


\section{References}

[1] Aghion, P., Bacchetta, P., and A. Banerjee, "A Simple Model of Monetary Policy and Currency Crises," European Economic Review, Papers and Proceedings 44, 2000, 728-738.

[2] Burnside, C., Eichenbaum, M. and S. Rebelo, "Hedging and Financial

Fragility in Fixed Exchange Rate Regimes," Federal Reserve Bank of Chicago, Working Paper No 99-11, 1999.

[3] Caballero, R., and A. Krishnamurthy, "Exchange Rate Volatility and the Credit Channel in Emerging Markets: A Vertical Perspective." WP, MIT, May 2004.

[4] Calvo, G. "Fixed vs. Flexible Exchange Rates: Preliminaries of a Turn-ofMillennium Rematch," mimeo, University of Maryland, 1999.

[5] Calvo, G. "Capital Market and The Exchange Rate With Special Reference to the Dollarization Debate in Latin America," Journal of Money, Credit and Banking 33, May 2001, 312-334.

[6] Calvo, G., and C. Reinhart, "Fear of Floating," Quarterly Journal of Economics, Vol. CXVIII, No. 2, May 2002.

[7] Chamon, M. and R. Hausmann, "Why Do Countries Borrow the Way they Borrow? WP, Harvard University, December 2002.

[8] Chari, V.V., and P. Kehoe, "Sustainable Plans," Journal of Political Economy 98 (1990), 783-802.

[9] Corsetti, G. and P. Pesenti, "Self-Validating Optimum Currency Areas." NBER Working Paper No. 8783, February 2002.

[10] Hausmann, R., E. Stein and U. Panizza, "Why Do Countries Float the Way they Float? WP 418, Inter-American Development Bank, 2002.

[11] Ize, A. and E. Levy-Yeyati, "Financial Dollarization." Journal of International Economics, Vol. 59, 2003.

[12] Ize, A. and E. Parrado, "Dollarization, Monetary Policy and the PassThrough," Working Paper \#188, International Monetary Fund, 2002.

[13] Jeanne, O., "Why Do Emerging Economies Borrow in Foreign Currency?" mimeo, IMF Research Department, October 2001.

[14] Krugman, P. "Balance Sheets, the Transfer Problem and Financial Crises," in: International Finance and Financial Crises, P. Isard, A. Razin and A. Rose (eds.), Kluwer Academic Publishers, 1999.

[15] Morón, E. and J. Castro, "Dedollarizing the Peruvian Economy: A Portfolio Approach," Universidad del Pacifico, September 2003. 
[16] Schneider, M. and A. Tornell, "Balance Sheets Effects, Bailout Guarantees and Financial Crises," mimeo, UCLA, 2000.

[17] Stein, E. H.; Hausmann, R.; Gavin, Michael; Pagés-Serra, C., "Financial Turmoil and Choice of Exchange Rate Regime," working Paper, Research Department, IADB, January 1999. Also in http://www.iadb.org/oce.

[18] Stokey, N., "Credible Public Policy," Journal of Economics Dynamics and Control 15 (1991), 627-56

[19] Tirole, J., "Inefficient Foreign Borrowing," American Economic Review 93 (2003), 1678-1702 


\begin{tabular}{llll}
\hline Agents & Central & Uncertainty & Trade, \\
write & Bank sets & is realized & production \\
contracts & policy & & and \\
& regime & & consumption \\
& & & take place
\end{tabular}

Figure 1 